Research Article

\title{
Constitutive Model and Deformation Characteristics of a Throat Insert Made of the $\mathrm{C} / \mathrm{C}$ Composite
}

\author{
Weiping Tian $\mathbb{D}^{1}$ and Chunguang Wang $\mathbb{D}^{2}$ \\ ${ }^{1}$ The Fourth Academy of China Aerospace Science and Technology Corporation, Xi'an 710025, China \\ ${ }^{2}$ State Key Laboratory for Strength and Vibration of Mechanical Structures, School of Aerospace Engineering, \\ Xi'an Jiaotong University, Xi'an 710049, China
}

Correspondence should be addressed to Chunguang Wang; king19850723@163.com

Received 1 June 2021; Revised 24 August 2021; Accepted 25 August 2021; Published 30 September 2021

Academic Editor: Hongbing Ding

Copyright (c) 2021 Weiping Tian and Chunguang Wang. This is an open access article distributed under the Creative Commons Attribution License, which permits unrestricted use, distribution, and reproduction in any medium, provided the original work is properly cited.

\begin{abstract}
Axial braided $\mathrm{C} / \mathrm{C}$ composite materials are widely applied in the throat insert of solid rocket motors. It is the key for the development and design of solid rocket motors to characterize accurately the macromechanical properties of the materials. The Jones-Nelson model is employed to characterize the constitutive relation of the axial braided $\mathrm{C} / \mathrm{C}$ composite material in this paper. The Jones-Nelson model is expanded and modified to characterize the $\mathrm{C} / \mathrm{C}$ composite under complex load conditions. The typical external load tests were carried out to verify the accuracy. On this basis, the deformation features of the axial braided $\mathrm{C} / \mathrm{C}$ composite throat insert are investigated during the working process of motors, and the strain of the throat insert during the working process is obtained by FEM. The strain and temperature in the outer surface of the throat insert are measured in the ground test of motors and are compared with the numerical results by FEM to verify the accuracy of the model. The results show that the result calculated based on the modified Jones-Nelson model by FEM is in a good agreement with the test result. It shows that the modified Jones-Nelson model can better describe the constitutive relation of $\mathrm{C} / \mathrm{C}$ composite materials, and it can be promoted to the engineering application of the throat insert of solid rocket motors.
\end{abstract}

\section{Introduction}

From the 1960s to the present, many scholars have devoted themselves to investigating nonlinear theories of composite materials and put forward various nonlinear theories. However, due to the lack of available test conditions and theories, it is difficult to systematically describe the entire mechanical behavior of materials in the micro- or mesoscale, and therefore, a unified pattern cannot be achieved. The constitutive relation theories established by researchers based on the continuum mechanics method can be summarized as follows: (a) nonlinear elastic theory, (b) elastic damage theory, (c) classical incremental plastic theory, and (d) endochronic theory [1]. The last three types of theories have strong pertinence and are not inconvenient for engineering applications because of their complex computation, which are mostly described by micro- and mesomechanics methods or by the FEM method. The first theory based on the macrome- chanics method is closely related to the elastic theory widely used, and it is easier to be introduced to engineering design [2].

In the study of the macroscopic nonlinear constitutive relation of composite materials, more frequently used theoretical models include the Petit nonlinear model, the Hahn-Tsai shear nonlinear model, the Hahn-Tsai lateral nonlinear modified model, and the Jones-Nelson nonlinear model [3]. Among them, the Jones-Nelson nonlinear constitutive model of composite materials is outstanding in solving nonlinear problems, which was established by Jones and Nelson using the relationship between the mechanical properties of composite materials and the strain energy density of the materials [4].

The throat insert as the critical component of the nozzle of solid rocket motors [5-8] is in a very harsh thermodynamic environment [9-11], and so the thermal structure design of the throat insert is an important part of solid 


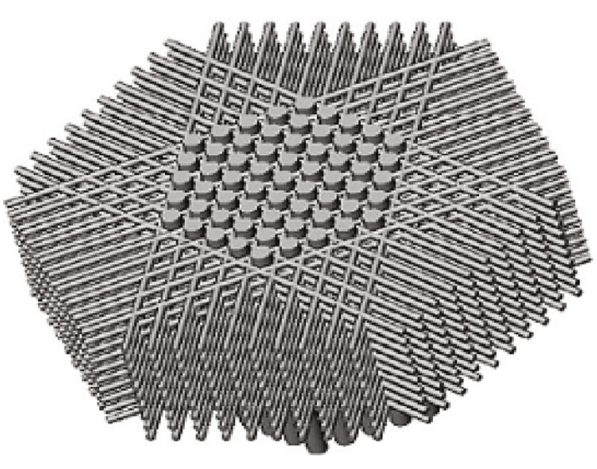

(a) 3D view

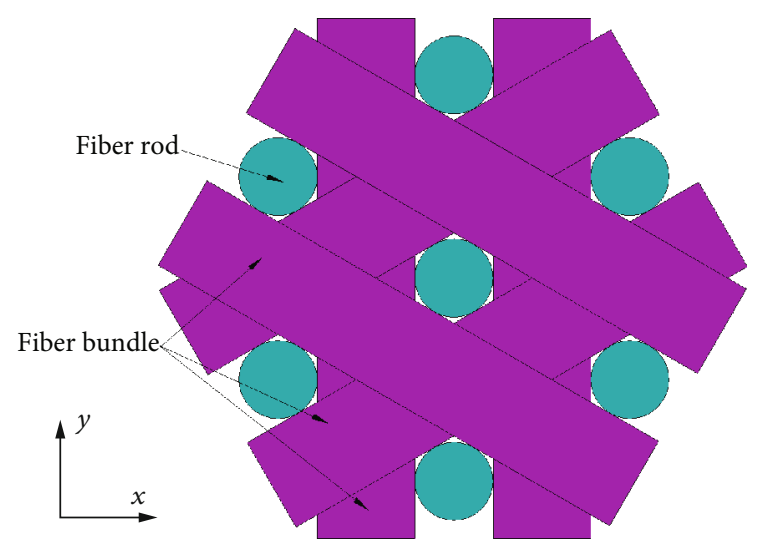

(b) Vertical view

FIgURE 1: The scheme of the braided method.

rocket motor design. Axial braided $\mathrm{C} / \mathrm{C}$ composite materials are extensively applied in the throat insert thermal structure of large solid rocket motors for their better thermodynamic properties [12-15]. However, due to the insufficient knowledge of the complex heterogeneous characteristics of the material, a constitutive model with good performance has been lacking for a long time, which leads to a large error in the calculation of the strain or stress field of the throat insert [16-20].

For better representation of the mechanical properties of axial braided $\mathrm{C} / \mathrm{C}$ composites, the Jones-Nelson constitutive model is extended in this paper, and the parameters in the model are obtained by the uniaxial tensile, compression, and shear tests. The thermomechanical coupling analysis of the throat insert structure is developed by FEM, and its distribution of temperature and strain is acquired. In order to verify the accuracy of the model, the temperature and strain variation over time at the corresponding position of the throat insert is measured and recorded via the ground tests. The results verify the accuracy of the model by comparing the result with the FEM result.

\section{The Constitutive Model of Axial Braided C/C Composite Materials}

In the multiaxial braided carbon fiber-reinforced carbon matrix composite material, the fiber rods by pultrusion molding form an axial reinforcement network and soft carbon fiber bundles are utilized to be woven into a prewoven body. The fiber rods are arranged in a regular triangle in the axial direction, while the fiber bundles pass through them successively from three channels of $0^{\circ}, 60^{\circ}$, and $120^{\circ}$ so that the increase in the interlayer is formed (as shown in Figure 1), and repeat this process until the desired dimension of the prewoven body is completed. Then, the prewoven body is machined by the bituminizing, carbonization, and densification process and high-temperature process to manufacture axial braided $\mathrm{C} / \mathrm{C}$ composites. The smallest unit of the prewoven body is symmetric along the axial direction, and the braided thickness is accumulated along the axial direction, so it is called the axial braided $\mathrm{C} / \mathrm{C}$ composite material.

2.1. Jones-Nelson Model. The occurrence of any damage form in nonlinear materials will be accompanied by different changes in strain energy and corresponding attenuation of stiffness, which will cause nonlinear constitutive relations of materials. Jones and Nelson proposed the following Jones-Nelson model according to the one-to-one relationship between material elastic properties and strain energy [3]:

$$
Y_{i}=A_{i}\left[1-B_{i}\left(\frac{U}{U_{0}}\right)^{C_{i}}\right]
$$

In the formula, $Y_{i}$ is the nonlinear mechanical property, usually the elastic modulus or Poisson's ratio.

$A_{i}, B_{i}$, and $C_{i}$ represent the initial slope, initial curvature, and initial curvature change rate of the $i$-th stress-strain curve, respectively; $U$ is the strain energy density; and $U_{0}$ is a constant that makes $U / U_{0}$ dimensionless.

There is no limit of the numbers and types of nonlinear mechanical properties in this model. The strain energy density in the equation is neither directional nor related to the selected coordinate system, and the form is concise. The constitutive relation of materials in all directions can be established by uniaxial mechanical tests in the main direction of the material, which facilitates engineering calculations. Thus, it can be widely used to describe the nonlinear performance of various composite materials.

2.2. The Extension of the Jones-Nelson Model. There is a limitation of the Jones-Nelson constitutive model when calculated; the strain energy density of the material must be less than the unidirectional strain energy density limit of the material. However, as for the highly anisotropic composite materials, especially when the materials are under complex load conditions, the materials are reinforced because of the 


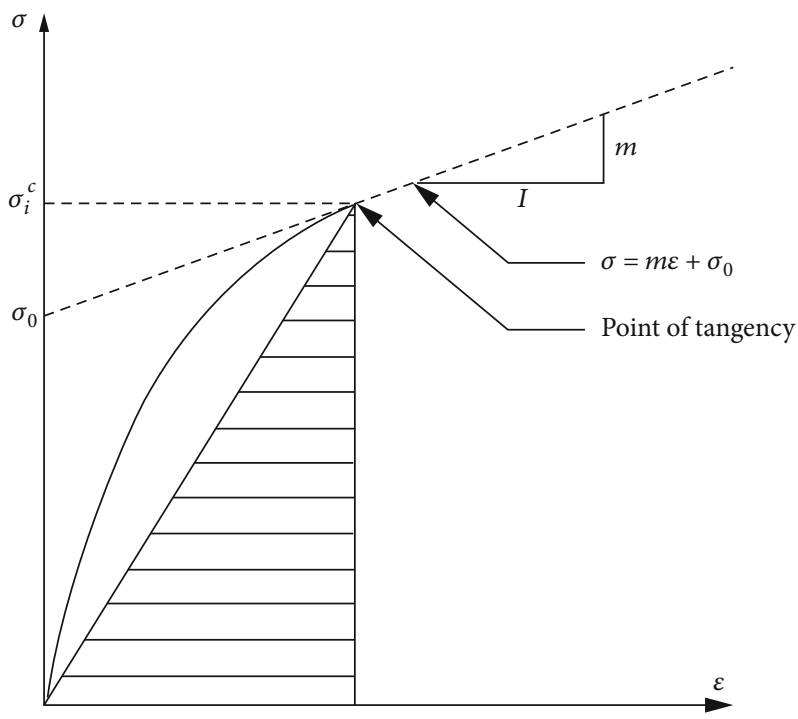

(a) The expanded theoretical scheme

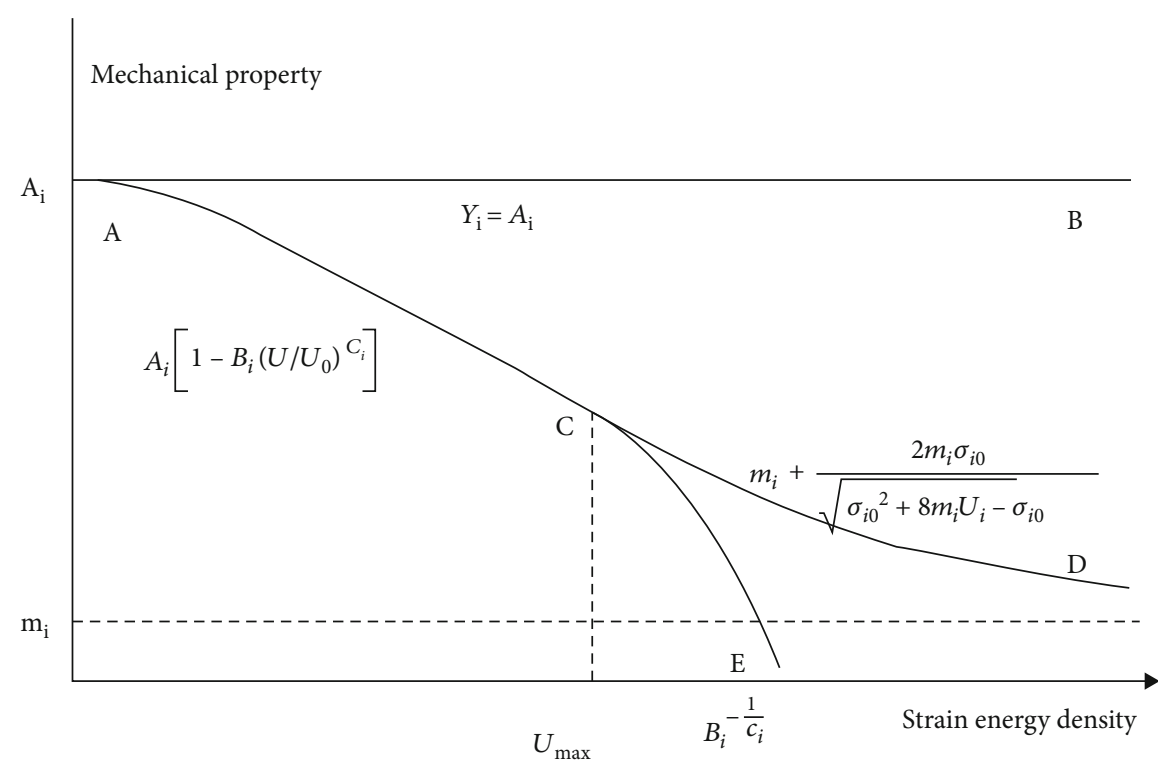

$\mathrm{AB}-\quad$ Linear constitutive model

ACD - Jones-Nelson extension model

ACE - Jones-Nelson model

(b) The scheme of the extended Jones-Nelson constitutive model

Figure 2: The extension of Jones-Nelson model.

damage evolution and the strain energy density is generally much greater than the uniaxial strain energy density limit. To deal with this limitation, the Jones-Nelson constitutive model needs to be expanded reasonably. When the material is in the damage evolution stage, the stress-strain curve is supplemented along the tangential direction, and the expanded theoretical scheme is displayed in Figure 2(a) [2]. The scheme of the extended Jones-Nelson constitutive model as shown in Figure 2(b) can also be obtained from the supplemented stress-strain curve model.
Based on equation (1), the segmented expression of the Jones-Nelson constitutive relation of axial braided C/C composites is constructed, as shown in

$$
Y_{i}= \begin{cases}A_{i}, & \sigma \leq \sigma_{0}^{c}, \\ A_{i}\left[1-B_{i}\left(\frac{U}{U_{0}}\right)^{C_{i}}\right], & \sigma>\sigma_{0}^{c} .\end{cases}
$$




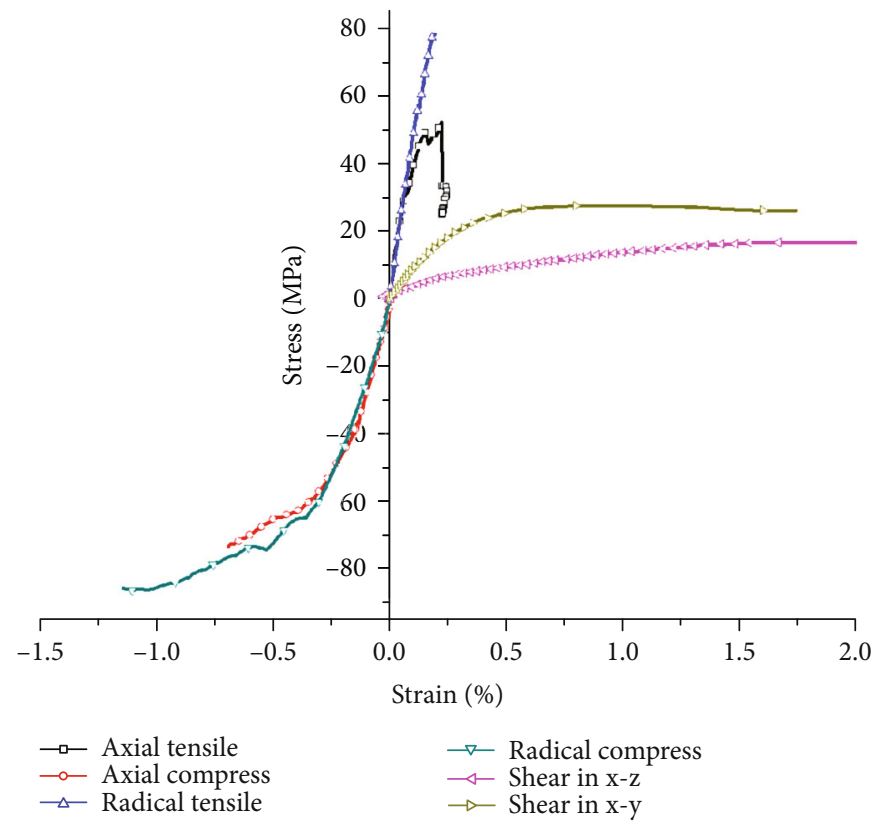

Figure 3: The typical stress-strain curves of axial braided C/C composites.

TABLE 1: The parameters of the modified Jones-Nelson model of axial braided $\mathrm{C} / \mathrm{C}$ composites.

\begin{tabular}{lcccccc}
\hline \multirow{2}{*}{ Tests } & \multirow{2}{*}{ Direction } & \multicolumn{5}{c}{ Parameters } \\
& & $\sigma_{0}^{c}$ & $A_{i}$ & $B_{i}$ & $C_{i}$ & $\sigma_{0}$ \\
\hline \multirow{2}{*}{ Tensile } & Axial & 30 & 52.67 & 0.0050 & 0.890 & 9.178 \\
& Radial & 30 & 49.46 & 0.0036 & 0.712 & 19.421 \\
\multirow{3}{*}{ Compression } & Axial & 50 & 22.36 & 0.564 & 0.047 & 54.865 \\
& Radial & 70 & 19.34 & 0.112 & 0.259 & 67.274 \\
Shear & Axial & 10.27 & 0.261 & 0.491 & 8.52 & 28.7 \\
& Radial & 3.78 & 0.073 & 1.048 & 22.06 & 12.5 \\
\hline
\end{tabular}

In the formula, $\sigma_{0}^{c}$ is the critical stress. When the stress is less than $\sigma_{0}^{c}$, the behavior of the material is linear elastic, while when the stress is more than $\sigma_{0}^{c}$, the behavior of the material is nonlinear elastoplastic.

The stress-strain curve of the materials is obtained via the tensile, compression, and shear tests as shown in Figure 3. The modified Jones-Nelson constitutive model is fitted through the data to acquire the constitutive parameters of the materials as shown in Table 1 in detail.

Tensile and shear tests of different batches of materials were conducted to verify the accuracy of the constitutive model proposed in this paper. The comparison between the test results and fitting results of the constitutive model is shown in Figure 4.

The experiments were carried out at room temperature, the INSTRON 5500R tensile test machine was used for the tensile test, the ASAN(MTS) 858 Mini Bionix compression test machine was used for the compression test, and the INSTRON 4505 universal test machine was used for the shear test. The strain measurement of tensile and compression test specimens was realized by measuring the surface strain of the specimen with the extensometer of the instru- ment. The strain of the specimen in the shear test was measured by the strain gauge on the specimen surface.

It can be found from Figure 4 that the results from the constitutive model proposed in this paper are in good agreement with the test values.

When the material is stretched, the axial elastic modulus is slightly greater than the radial elastic modulus in the elastic stage, while in the elastoplastic stage, the nonlinearity in the axial direction is significant and the modulus gradually decreases with increasing load.

When the material is compressed, the radial elastic modulus of the material is slightly greater than the axial elastic modulus in the elastic stage, while in the elastoplastic stage, the nonlinearity of two directions is significant and the modulus decreases rapidly with increasing load.

The axial braided C/C composites have obviously dualmodulus features of tensile and compression, of which the tensile modulus is significantly greater than the compression modulus.

The nonlinear behavior of axial braided C/C composites is more obvious under the shear loading. During the process, they show nonlinear behavior except for the weak linear elastic characteristics in the initial stage.

\section{Calculation of the Structural Deformation Characteristics of the Throat Insert}

In the axial tensile test, the calculated results are in good agreement with the test results in the range of $0.06 \%$ strain. As the strain continues to be increased, the calculation error increases gradually, and the maximum is within $28 \%$. In the axial compression test, the calculated results are in good agreement with the test results in the range of $0.4 \%$ strain. As the strain continues to be increased, the calculation error increases gradually and the maximum is within $8.3 \%$. 


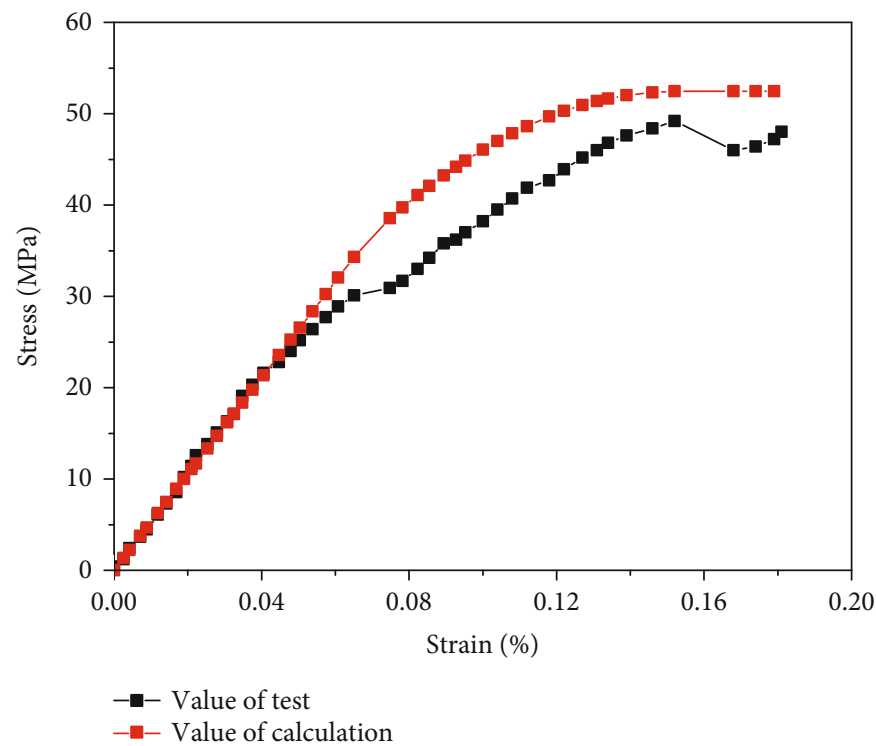

(a) Axial tension

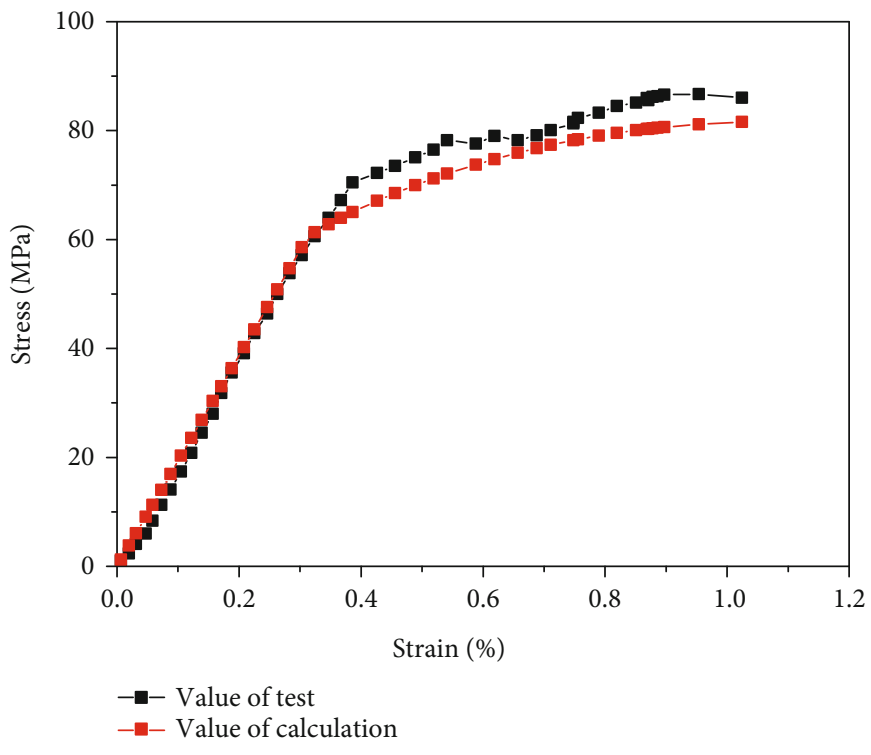

(b) Axial compression

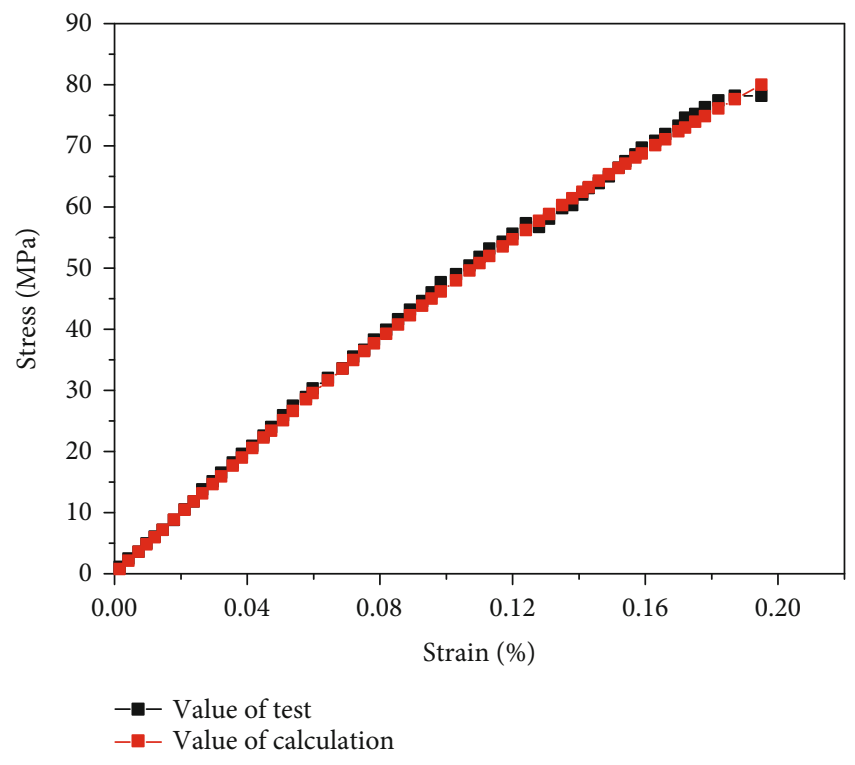

(c) Radial tension

Figure 4: Continued. 


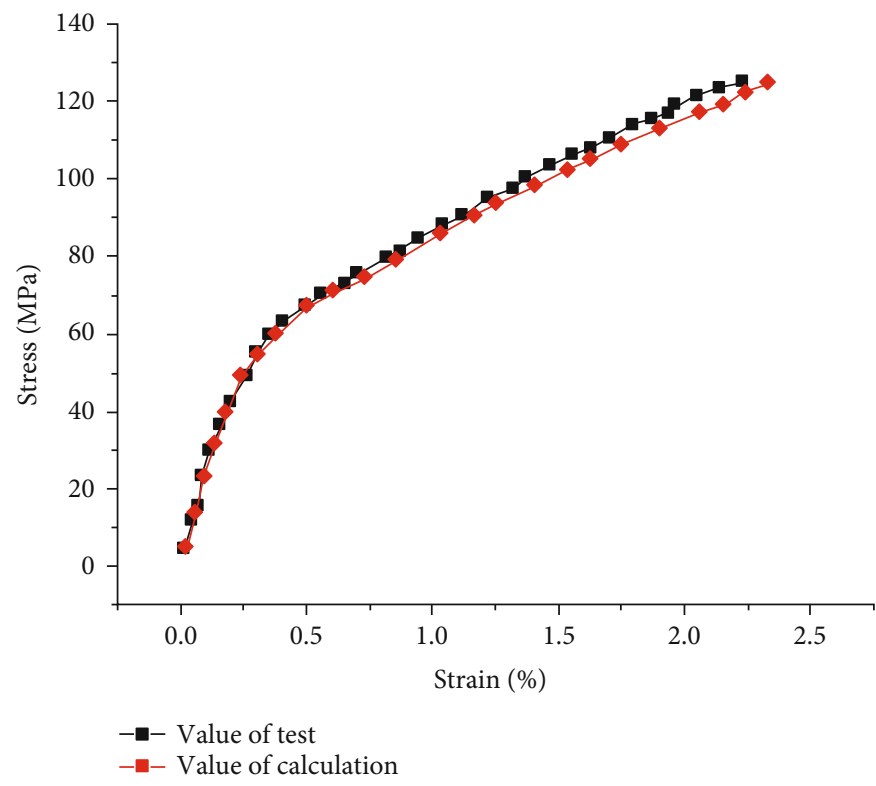

(d) Radial compression

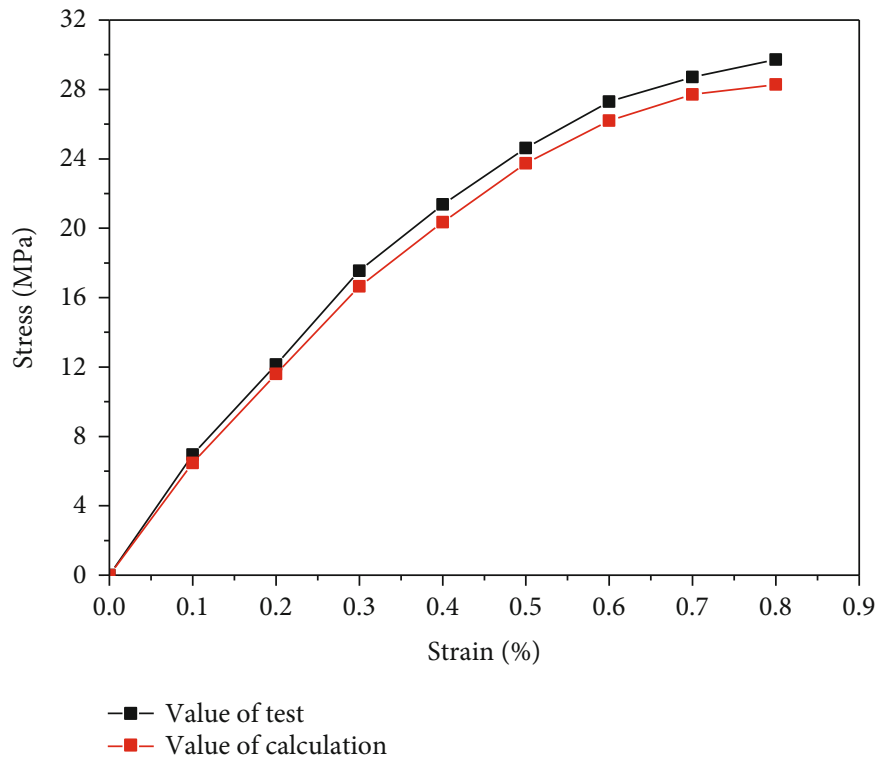

(e) Outer-face shear

FIgUre 4: The predicted curves of the constitutive model compared with the test curves.

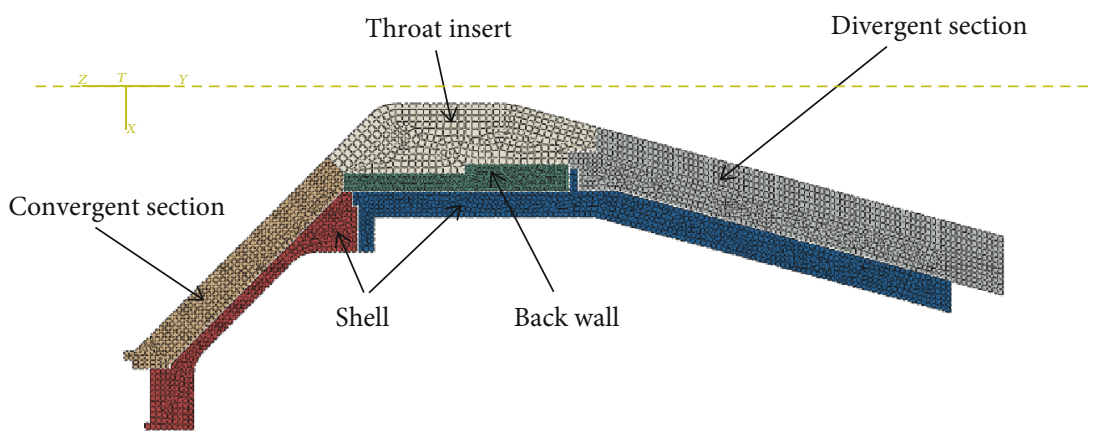

Figure 5: The finite element model of one solid rocket motor nozzle. 
TABLe 2: Performance parameters of nozzle materials.

\begin{tabular}{|c|c|c|c|c|c|}
\hline Component & Throat insert & Divergent section & Back wall & Convergent section & Shell \\
\hline Material & $\begin{array}{l}\text { Axial braided } \\
\text { C/C }\end{array}$ & $\begin{array}{l}\text { Carbon cloth } \\
\text { winding }\end{array}$ & $\begin{array}{l}\text { High silicon oxygen cloth } \\
\text { winding }\end{array}$ & $\begin{array}{l}\text { Carbon Fiber } \\
\text { molding }\end{array}$ & 30CrMnSiA \\
\hline Modulus GPa & \multirow{2}{*}{ Jones-Nelson } & 12.2 & 17 & 10.8 & 210 \\
\hline Poisson ratio & & 0.1 & 0.12 & 0.1 & 0.3 \\
\hline Density $\times 10^{3} \mathrm{~kg} / \mathrm{m}^{3}$ & 1.95 & 1.45 & 1.65 & 1.4 & 7.8 \\
\hline Specific heat $(\mathrm{J} /(\mathrm{kg} \cdot \mathrm{K}))$ & 2100 & 920 & 850 & 1000 & 473 \\
\hline $\begin{array}{l}\text { Thermal conductivity (W/ } \\
(\mathrm{m} \cdot \mathrm{K}))\end{array}$ & 85 & 1 & 0.6 & 1.5 & 50 \\
\hline Coefficient of expansion $\times 10^{-6}$ & 1 & 4.2 & 12 & 10 & 13 \\
\hline
\end{tabular}

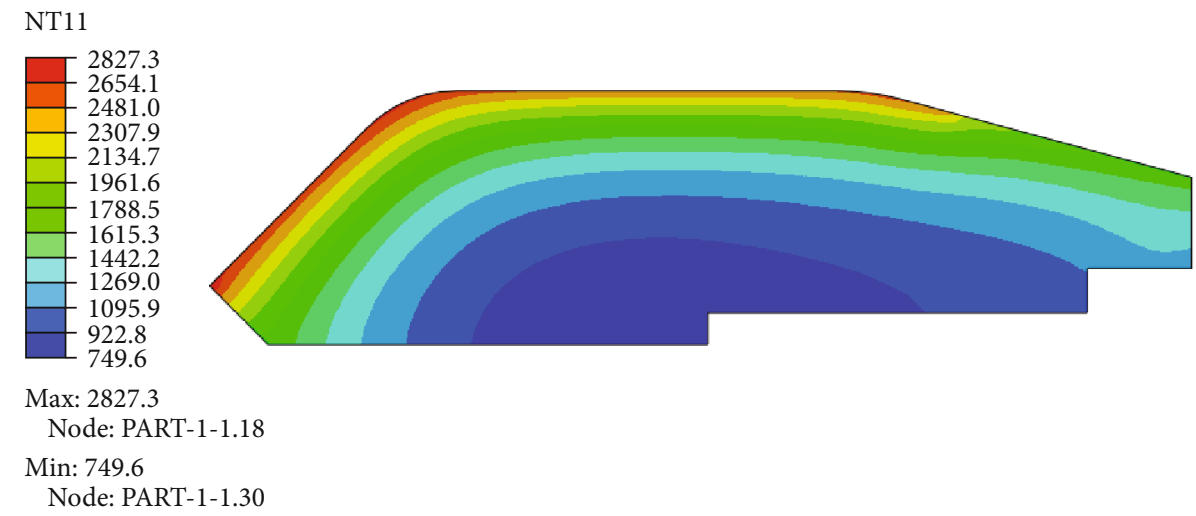

Figure 6: Temperature contour at $20 \mathrm{~s}$ (the unit is $k$ ).

In the radial tensile test, the calculated results of the model are in good agreement with the test results, and the error is less than $2 \%$. In the radial compression test, the calculated results are in good agreement with the test results in the range of $1 \%$ strain. As the strain continues to be increased, the calculation error increases gradually, and the maximum is within $6 \%$.

In the shear test, the model calculation results are consistent with the test results, and the error increases gradually with the increase in strain, and the maximum error is less than $8 \%$.

3.1. Finite Element Model and the Algorithm. The finite element model of the solid rocket motor nozzle is shown in Figure 5, which consists of 5 parts, including throat insert, divergent section, convergent section, back wall, and shell. Their material parameters are shown in Table 2.

The convective heat transfer coefficient, wall temperature, and wall pressure distribution are necessary in calcu- lating the nozzle temperature distribution and thermal stress field by the engineering algorithm. The convective heat transfer coefficient $h_{c}$ is determined by the Bartz formula:

$$
h_{c}=\left(\frac{0.026}{d_{t}^{0.2}}\right)\left(\frac{\mu^{0.2} c_{p}}{p_{r}^{0.6}}\right)\left(\frac{P_{0} g}{C^{*}}\right)^{0.8}\left(\frac{d_{t}}{r_{c}}\right)^{0.1}\left(\frac{A_{t}}{A}\right)^{0.9} \sigma_{1},
$$

where $d_{t}$ is the nozzle throat insert diameter, $\mu$ is the gas dynamic viscous coefficient, $c_{p}$ is the gas constant pressure-specific heat capacity, $p_{r}$ is the gas Prandtl number, $P_{0}$ is the gas total pressure at the nozzle inlet, $C^{*}$ is the gas characteristic velocity, $r_{c}$ is the radius of nozzle throat insert curvature, $A_{t}$ is the nozzle throat insert area, $A$ is the area of the computed section, and $\sigma_{1}$ is the correction factor of the convective heat transfer coefficient.

$$
\sigma_{1}=\frac{1}{\left[(1 / 2)\left(T_{w} / T_{0}\right)\left(1+((k-1) / 2) M a^{2}\right)+0.5\right]^{0.65}\left(1+((k-1) / 2) M a^{2}\right)^{0.15}} .
$$


E, E22

(Avg: $75 \%$ )

\begin{tabular}{r} 
\\
\hline \\
-0.002907 \\
0.002436 \\
0.002200 \\
0.001965 \\
0.001729 \\
0.001494 \\
0.001258 \\
0.001023 \\
0.000787 \\
0.000552 \\
0.000316 \\
0.000081
\end{tabular}

Max: 0.002907

Elem: PART-1-1.1193

Node: 344

Max: 0.00008

Elem: PART-1-1.1432

Node: 30

(a) The axial strain contour without considering the Jones-Nelson constitutive model

E, E22

(Avg: 75\%)
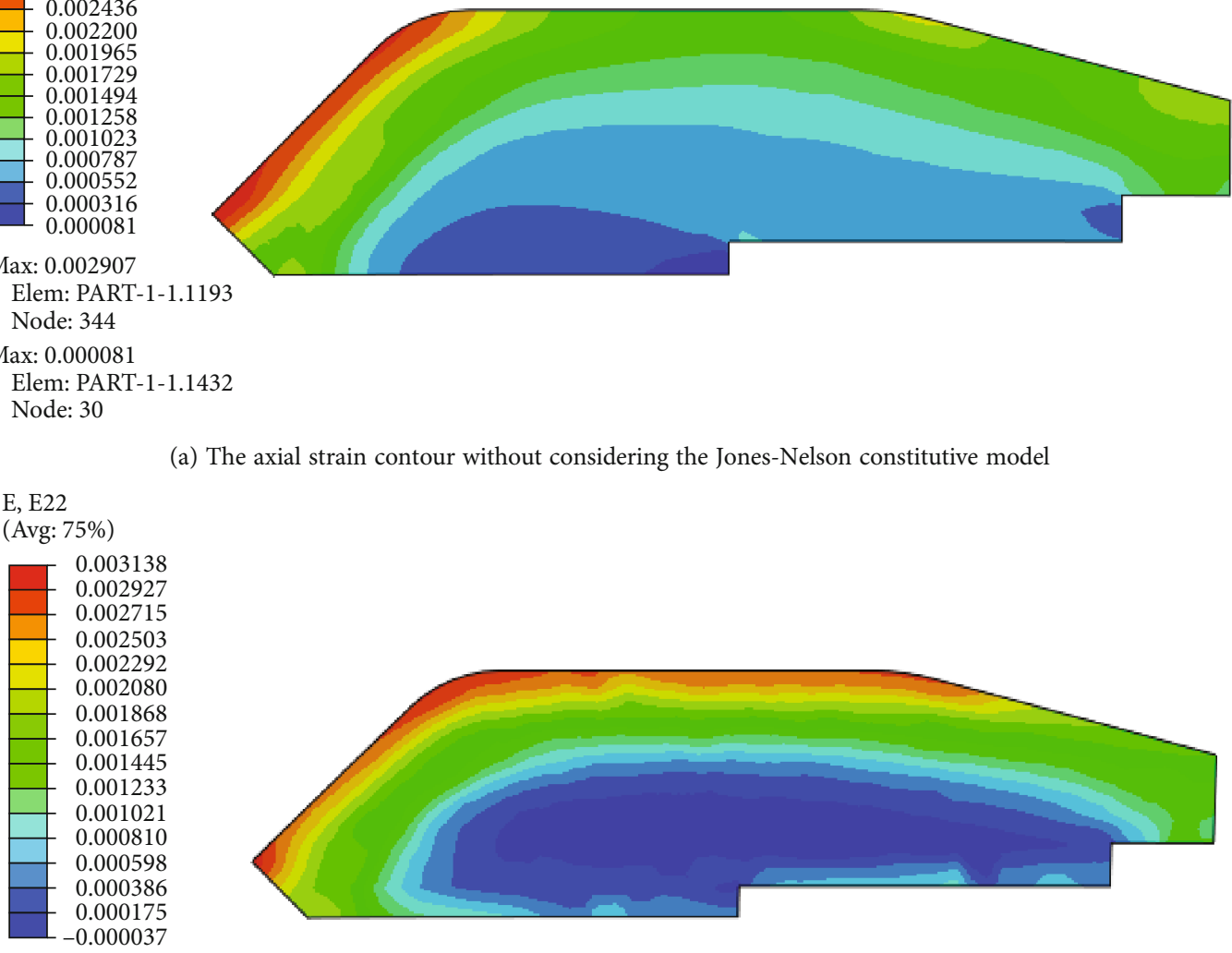

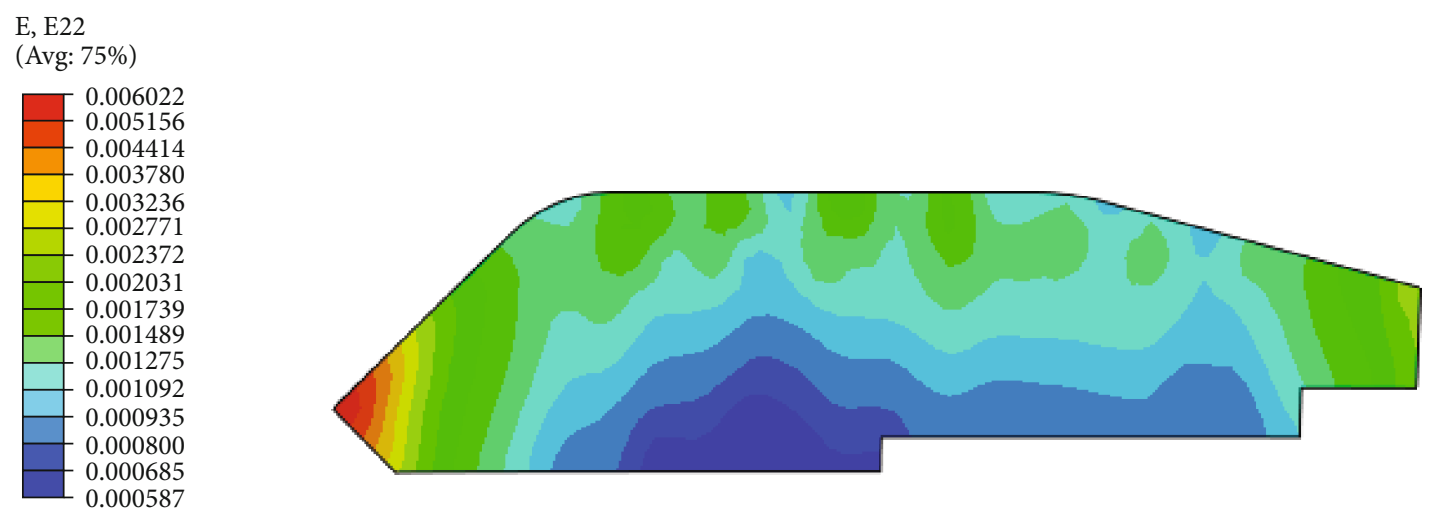

Max: 0.006022

Elem: PART-1-1.1429

Node: 18

Min: 0.000587

Elem: PART-1-1.1222

Node: 365

(d) The hoop strain contour considering the Jones-Nelson constitutive model

FIGURE 7: Strain contours at 5 seconds.

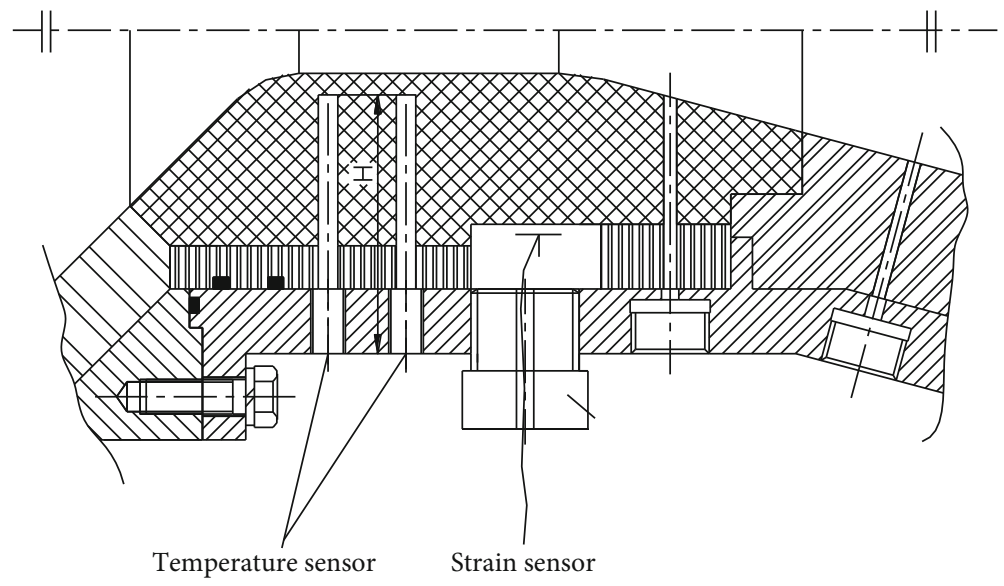

Figure 8: Test nozzle.

The quasi-one-dimensional isentropic flow in the nozzle can be solved by the following equation.

$$
\begin{gathered}
\frac{T_{0}}{T}=1+\frac{k-1}{2} \mathrm{Ma}^{2}, \\
\frac{P_{0}}{P}=\left(1+\frac{k-1}{2} \mathrm{Ma}^{2}\right)^{k /(k-1)}, \\
\frac{A}{A_{t}}=\frac{1}{\mathrm{Ma}}\left[\frac{(k-1) \mathrm{Ma}^{2}+2}{k+1}\right]^{(k+1) / 2(k-1)},
\end{gathered}
$$

where $k$ is the specific heat ratio of gas, $T_{0}$ is the gas total temperature at the nozzle inlet, $P_{0}$ is the gas total pressure at the nozzle inlet, $T_{w}$ is the wall temperature at the computed section, $T$ is temperature at the computed section, and $M a$ is the March number at the computed section.

3.2. Boundary Conditions and the Discrete Method. The simplified axisymmetric model was also applied in the solid domain calculation. Localized grid refinement was adopted in the stress concentration area. The selected calculation element CAX4RT which had taken the calculation of temperature and stress into account could obtain more accurate results. The calculation model is shown in Figure 4. The number of grids is about 200,000 .

The interface of the throat insert and insulation is set as the contact condition, and the friction coefficient is 0.25 . Besides, the other interfaces of other components are set as binding. The material parameters of each component are shown in Table 1. The coupled temp-displacement 
(transient) analysis step was applied, and the calculation time was $20 \mathrm{~s}$.

The initial temperature of the nozzle is $20^{\circ} \mathrm{C}$, the gas temperature in the combustion chamber is $T_{0}=3450 \mathrm{~K}$, and the gas pressure is $\rho_{0}=6.25 \mathrm{MPa}$ during the calculation. The flange plate shell at the inlet of the nozzle is fixed in the axial direction, and the outer wall of the nozzle is in an adiabatic condition.

3.3. The Analysis of the Temperature Field. After the analysis of the overall thermal structure of the nozzle, only the temperature field and strain field of the throat insert are analyzed.

Figure 6 displays the temperature contour of the throat insert at $20 \mathrm{~s}$. It can be found that the highest temperature $2554^{\circ} \mathrm{C}$ is located at the entrance of the column section, while the lowest temperature $477^{\circ} \mathrm{C}$ is at the junction part of the throat insert and the back wall.

3.4. The Analysis of the Strain Field. The temperature of the strain gauge is $126^{\circ} \mathrm{C}$ at $5 \mathrm{~s}$, which reaches the critical point of the adhesive failure. Therefore, the strain field only before $5 \mathrm{~s}$ is extracted for analysis.

Figure 7 (a) shows the axial strain contour of the throat insert at $5 \mathrm{~s}$ without considering the Jones-Nelson constitutive model. It can be seen from the figure that the axial strain at $5 \mathrm{~s}$ is all positive. The maximum strain $2907 \mu \varepsilon$ is located at the junction part of the inner wall of the throat insert and the convergence section, while the minimum strain 81 $\mu \varepsilon$ is located at the junction part of the outer wall of the throat insert and the back wall.

Figure 7 (b) shows the axial strain contour of the nozzle throat insert at $5 \mathrm{~s}$ considering the Jones-Nelson constitutive model. It can be seen from the figure that the axial strain at $5 \mathrm{~s}$ is positive near the inner wall of the throat insert, but it is negative near the outer wall of the throat insert close to the back wall. The maximum strain $3138 \mu \varepsilon$ is located at the junction part of the inner wall of the throat insert and the convergence section, while the minimum strain $-37 \mu \varepsilon$ is located at the outer wall of the throat insert near the back wall.

Figure 7(c) exhibits the hoop strain contour of the throat insert without considering the Jones-Nelson constitutive model. It can be seen from the figure that all hoop strains at $5 \mathrm{~s}$ are positive. The maximum strain $3747 \mu \varepsilon$ is located at the connection part between the inner wall of the throat insert and the convergence section, while the minimum strain $666.8 \mu \varepsilon$ is located at the connection part between the outer wall of the throat insert and the back wall.

Figure $7(d)$ exhibits the hoop strain contour of the throat insert at $5 \mathrm{~s}$ considering the Jones-Nelson constitutive model. It can be seen from the figure that the hoop strain at $5 \mathrm{~s}$ is all positive. The maximum strain $6022 \mu \varepsilon$ is located at the connection part between the inner wall of the throat insert and the convergence section, while the minimum strain $586.6 \mu \varepsilon$ is located at the connection part between the outer wall of the throat insert and the back wall.

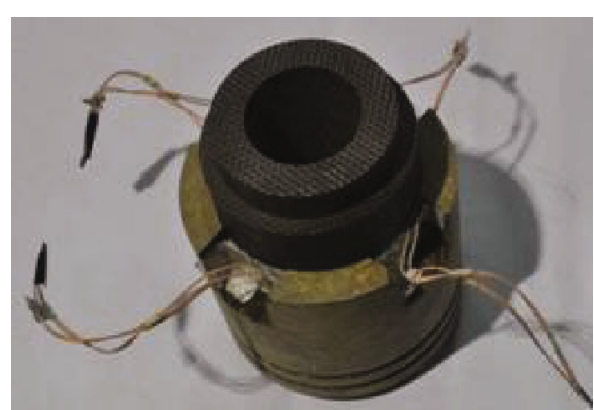

Figure 9: The throat insert bonded with strain gauges.

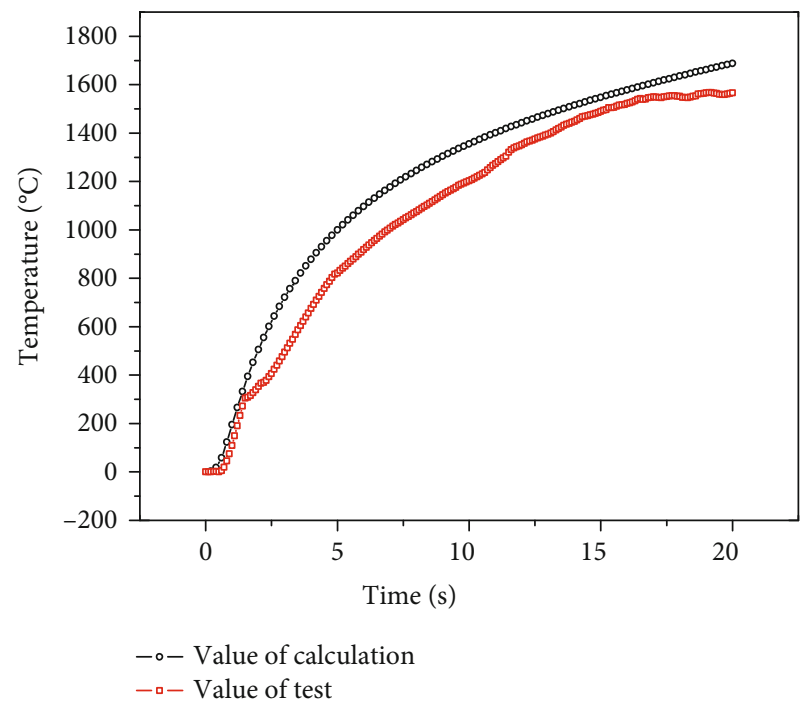

Figure 10: The comparison between calculated results and test results of the temperature field.

\section{The Discussion of the Ground Test Results}

4.1. The Motors in the Tests and Measurement Location. The test is conducted by utilizing the $\Phi 339$ standard test motor with an HTPB-type propellant, the maximum temperature of the combustion chamber is $3450 \mathrm{~K}$, the maximum working pressure is $7.5 \mathrm{MPa}$, the average working pressure is 6.25 $\mathrm{MPa}$, and the working time lasts $20 \mathrm{~s}$.

The nozzle structure is shown in Figure 8. According to the test requirements, the temperature sensors $T$ are embedded at different positions in the axial direction of the throat insert. The strain sensors $S_{1}$ (in the axial direction) and $S_{2}$ (in the circular direction) are embedded on the outer surface of the throat insert.

The thermocouple is installed on the drilled throat insert to measure the temperature of the nozzle. Because the platinum-rhodium thermocouple is easily damaged, the tungsten rhenium-tungsten rhenium thermocouple is utilized in the high-temperature area of the throat insert, and the K-type nickel chromium-nickel silicon thermocouple is employed in the low-temperature area. 


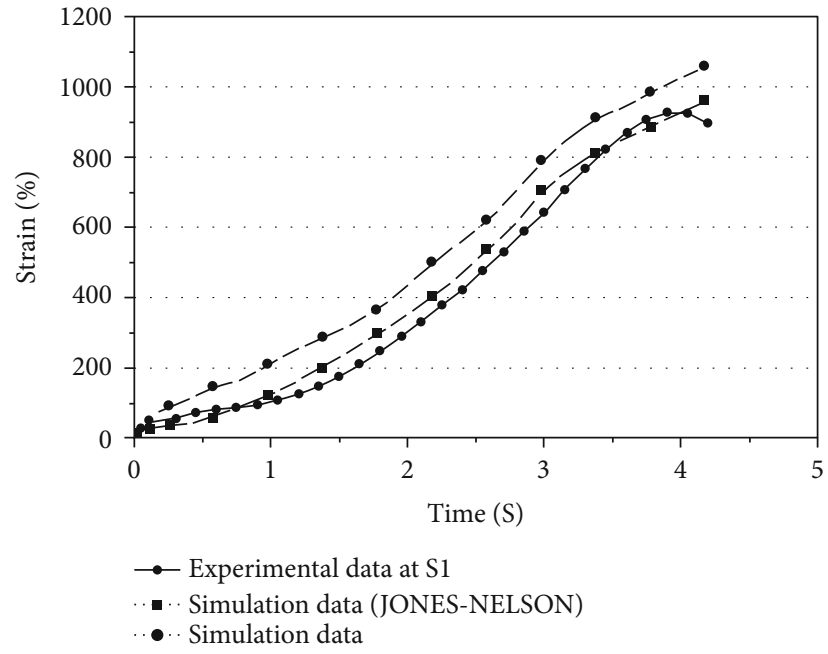

(a) Strain at location $S_{1}$

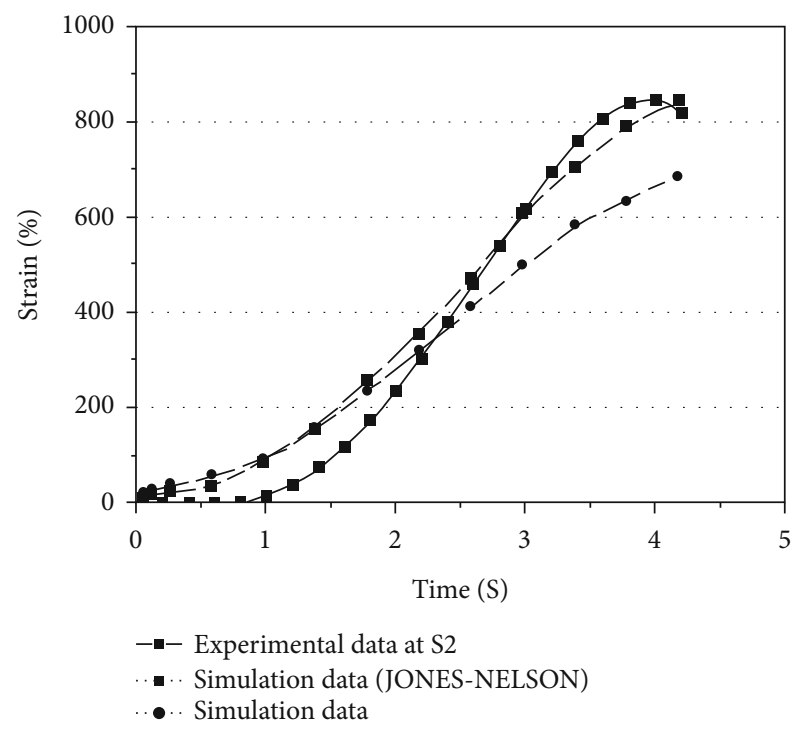

(b) Strain at location $S_{2}$

Figure 11: Test strain data and simulation strain data of each strain gauge.

The high-temperature strain gauge of the throat insert is selected as the BB (BAB) 120-4AA250 foil strain gauge with a temperature self-compensation function produced by China Aviation Electric Testing Co., Ltd. Its test temperature range is $-40 \sim 250^{\circ} \mathrm{C}$, and the bonding is NP-50 hightemperature glue. Figure 9 shows the throat insert bonded with the temperature sensors and high-temperature strain gauges.

4.2. The Analysis of the Test Temperature Field. The temperature variation during the working process of the motor is extracted at first and compared with the numerical calculation results, as shown in Figure 10. The calculated results are in good agreement with the test results, and the varying trend is quite similar. The calculated value is slightly higher than the measured value, which may result from the finite element calculation without considering the self-ablation effect of the throat insert. The maximum calculation deviation of the temperature field is $\leq 9.1 \%$.

4.3. The Analysis of the Test Strain Field. The strain varied curve before $5 \mathrm{~s}$ is compared with the numerical calculation result, as shown in Figure 11.

As shown in Figure 11(a), the test curve of the axial strain is in good continuity. The highest axial strain 916.20 $\mu \varepsilon$ at the location of $S_{1}$ appears at $3.87 \mathrm{~s}$. In the computation without considering the Jones-Nelson constitutive model, the axial strain reaches $992.4 \mu \varepsilon$ at $3.87 \mathrm{~s}$, and the error with the test data is $8.3 \%$. In the computation considering the Jones-Nelson constitutive model, the axial strain reaches $894.3 \mu \varepsilon$ at $3.87 \mathrm{~s}$, and the error with the average value of the test data is $2.0 \%$.

The test curve of the hoop strain has a good continuity and consistency as shown in Figure 11(b). The highest strain at location $S_{2}$ appears at $3.89 \mathrm{~s}$, which is $844.64 \mu \varepsilon$. In the computation without considering the Jones-Nelson consti- tutive model, the hoop strain reaches $644.1 \mu \varepsilon$ at $3.89 \mathrm{~s}$, and the error with the test data is $23.6 \%$. In the computation considering the Jones-Nelson constitutive model, the hoop strain reaches $802.8 \mu \varepsilon$ at $3.89 \mathrm{~s}$, and the error with the average value of the test data is $4.9 \%$. So, the conclusion is that the computation result considering the Jones-Nelson constitutive model is more accurate.

\section{Conclusions}

(1) The Jones-Nelson model is extended and modified in this paper. The new model can express the mechanical properties of axial braided $\mathrm{C} / \mathrm{C}$ composites under complex loading conditions. Also, the model is verified by the typical tensile, compression, and shear tests

(2) The thermal-mechanical coupling numerical computation and analysis of the motor nozzle in the working process are implemented. The temperature and strain distributions of the throat insert are obtained, which can be applied to the calculation and analysis of the thermal structure of the throat insert

(3) The numerical results are compared with the result of ground ignition tests. The results show that the calculation results considering the Jones-Nelson model are more consistent with the test results, which further verifies the reasonability of the JonesNelson extended model.

\section{Data Availability}

As most of the data in this manuscript were related to trade secrets, the authors cannot provide them completely. In the 
future, if necessary, the authors can share some data with reviewers or readers.

\section{Conflicts of Interest}

The authors declare that there is no conflict of interest regarding the publication of this paper.

\section{Acknowledgments}

This article was funded by the Xi'an Jiaotong University and the Natural Science Basic Research Program of Shaanxi Province (2021JQ-527).

\section{References}

[1] H. Tan, L. Yufen, and D. Xingwen, "Refined Jones-Nelson physical nonlinear material model and rubber lamina analysis," Acta Mechanica Solida Sinica, vol. 19, no. 1, pp. 15-25, 1998.

[2] H. Tan, L. Yuyan, and D. Xingwen, "An improved JonesNelson nonlinear material model and rubber composite lamina analysis," Acta Mechanica Solida Sinica, vol. 19, no. 1, pp. 28-36, 1998.

[3] C. Tian-yu, S. Hong-bin, T. Min, L. Geng, and X. Cheng-hai, "Analysis of $\mathrm{C} / \mathrm{C}$ composites throat distortion based on the Jones-Nelson constitutive model," Journal of Solid Rocket Technology, vol. 40, no. 4, pp. 414-419, 2017.

[4] M. Albano, A. Delfini, and R. Pastore, "A new technology for production of high thickness carbon/carbon composites for launchers application," Acta Astronautica, vol. 128, pp. 277285, 2016.

[5] K. N. Shivakumar and A. Cozart, "Analysis of 3-D braided composite ablative rocket nozzle," in ASME 2002 Fluids Engineering Division Summer Meeting, pp. 1-8, 2002.

[6] S. U. Jun-ming, Z. H. O. U. Shao-jian, X. U. E. Ning-juan et al., "Effect of nozzle thermal environment on the ablation rate of the throat inserts of solid rocket motors," New Carbon Materials, vol. 33, no. 5, pp. 442-448, 2018.

[7] S. J. Park and M. S. Cho, "Effect of anti-oxidative filler on the interfacial mechanical properties of carbon-carbon composites measured at high temperature," Carbon, vol. 38, no. 7, pp. 1053-1058, 2000.

[8] D. Bianchi, F. Nasuti, and E. Martelli, "Coupled analysis of flow and surface ablation in carbon-carbon rocket nozzles," Journal of Spacecraft and Rockets, vol. 46, no. 3, pp. 492-500, 2012.

[9] X. Hou, W. Cheng, N. Chen, and H.-y. Zhou, "Preparation of a high performance carbon/carbon composite throat insert woven with axial carbon rods," Carbon, vol. 67, 2014.

[10] Y. Guo, H.-y. Xie, J. Zeng-rong, and X. Zhi-xiang, "Mechanical properties and thermal shock resistance of rhenium coating in iridium/rhenium/carbon-carbon composites," Procedia Engineering, vol. 99, pp. 1407-1414, 2015.

[11] D. Bianchi, F. Nasuti, M. Onofri, and E. Martelli, "Thermochemical erosion analysis for chraphite/carbon-carbon rocket nozzles," Journal of Propulsion and Power, vol. 27, no. 1, pp. 197-205, 2011.

[12] C. Wang, T. Min, and L. Weikai, "Study on microstructure characteristics of axially braided carbon/carbon composites based on SEM and micro-CT,” Materials, vol. 13, no. 6, 2020.
[13] C. Wang, P. Cao, M. Tang, W. Tian, K. Liu, and B. Liu, "Study on properties prediction and braiding optimization of axial braided carbon/carbon composite," Materials, vol. 13, no. 11, p. 2588, 2020.

[14] J. Lili, W. Rina, X. Meiling, L. Zhenguo, and Z. Xinwei, "Experimental investigation on the tensile and compressive properties of 3D 4-directional braided carbon fiber/epoxy resin composites in thermal environment," Procedia Engineering, vol. 37, no. 2, pp. 309-317, 2020.

[15] J.-J. Gou, W.-Z. Fang, Y.-J. Dai, S. Li, and W.-Q. Tao, "Multisize unit cells to predict effective thermal conductivities of 3D four-directional braided composites," Composite Structures, vol. 163, 2017.

[16] J.-J. Gou, Z. Hu, Y.-J. Dai, S. Li, and W.-Q. Tao, "Numerical prediction of effective thermal conductivities of $3 \mathrm{D}$ fourdirectional braided composites," Composite Structures, vol. 125, 2015.

[17] C. Wang, T. Weiping, and T. Min, "Study on mechanical properties and failure mechanism of axial braided C/C composite," International Journal of Aerospace Engineering, vol. 2021, 12 pages, 2021.

[18] L. Lazzarotto, L. Dubar, A. Dubois, P. Ravassard, and J. Oudin, "Identification of Coulomb's friction coefficient in real contact conditions applied to a wire drawing process," Wear, vol. 211, no. 1, pp. 54-63, 1997.

[19] E. V. Morozov and J. F. P. P. de la Beaujardiere, "Numerical simulation of the dynamic thermostructural response of a composite rocket nozzle throat," Composite Structures, vol. 91, no. 4, pp. 412-420, 2009.

[20] S. Lin, B. Futing, Z. Ning et al., "Thermo-structural response caused by structure gap and gap design for solid rocket motor nozzles," Energies, vol. 9, no. 6, pp. 430-435, 2016. 